Cukurova Üniversitesi Mühendislik Mimarlık Fakültesi Dergisi, 33(2), ss. 45-56, Haziran 2018

Çukurova University Journal of the Faculty of Engineering and Architecture, 33(2), pp. 45-56, June 2018

\title{
Hibrit Donatılı Basit Mesnetli Betonarme Kirişlerin Yük-Deplasman Davranışının İncelenmesi
}

\author{
İsmail ÜNSAL ${ }^{* 1}$, Serkan TOKGÖZ ${ }^{2}$, İsmail H. ÇAĞATAY ${ }^{1}$, Cengiz DÜNDAR $^{1}$ \\ ${ }^{I}$ Çukurova Üniversitesi, Mühendislik Fakültesi, İnşaat Mühendisliği Bölümü, Adana \\ ${ }^{2}$ Adana Bilim ve Teknoloji Üniversitesi, Mühendislik Fakültesi, Inşaat Mühendisliği Bölümü, \\ Adana
}

Geliş tarihi: 06.04.2018

Kabul tarihi: 22.05.2018

$\ddot{\mathbf{O} z}$

Bu çalışmada, hibrit donatılı betonarme kirişlerin yük-deplasman davranışı teorik olarak incelenmiştir. Hibrit donatılı betonarme kesitlerde, çekme veya basınç bölgesinde cam elyaf lifli polimer (GFRP) ve çelik donatılar bir arada kullanılmaktadır. Çalışmada, test verileri literatürde mevcut olan hibrit donatılı (GFRP ve çelik) basit mesnetli 6 adet betonarme kiriş numunesi esas alınmış ve kirişler sayısal bir yöntemle analiz edilmiştir. Kirişlerin yük-deplasman ilişkileri teorik olarak elde edilmiş ve sonuçlar mevcut deneysel çalışmada verilen yük-deplasman eğrileriyle karşılaştırılmıştır. Sayısal yöntemde kirişlerin çatlamış durumdaki efektif eğilme rijitliklerinin hesabında çatlamış kesit analizi ile hesaplanan moment-eğrilik ilişkileri esas alınmaktadır. Sistem deplasmanlarının hesabında rijitlik matrisi yöntemi kullanılmaktadır. Sayısal yönteme dayalı olarak elde edilen yük-deplasman eğrilerinin deneysel sonuçlar ile uyum içerisinde olduğu gözlenmiştir.

Anahtar Kelimeler: Hibrit donatılı kiriş, FRP donatı, Yük-deplasman, Moment-eğrilik

\section{Investigation of Load-Displacement Behavior of Hybrid Reinforced Simply Supported Concrete Beams}

\begin{abstract}
In this study, load-deflection behavior of hybrid reinforced (GFRP and steel) concrete beams is theoretically investigated. Six hybrid reinforced (GFRP and steel) simply supported concrete beams available in literature were considered and analyzed based on a numerical method. The load-deflection curves of beams are obtained theoretically and the results are compared with the load-deflection curves given in the available experimental study. The moment-curvature relationships calculated by cracked section analysis is taken as basis for the effective flexibilities of the beams in cracked state. The stiffness matrix method is used in the structural analysis. It is observed that the load-deflection curves obtained based on the numerical procedure is in good agreement with the available test results.
\end{abstract}

Keywords: Hybrid reinforced beam, FRP reinforcement, Load-deflection, Moment-curvature

"Sorumlu yazar (Corresponding author): İsmail ÜNSAL, ismailunsl@gmail.com 


\section{GíRiş}

Lifli polimer donatıların (FRP) inşaat sektöründe kullanımı, yüksek kapasitede çekme dayanımı, yüksek korozyon direnci, çevresel ve kimyasal etkilere karşı yüksek dayanım göstermesi özellikleri nedeniyle günden güne hız kazanmaktadır. Lifli polimerler betonarme elemanlarda çelik donatının yerine kullanılabildiği gibi elemanların eğilme ve kesme kapasitelerini iyileştirmek amacıyla güçlendirme malzemesi olarak da kullanılmaktadırlar.

Karbon, bazalt, aramid ve cam lifli olarak üretilmekte olan lifli polimer donatıların en önemli dezavantajı uzama kapasitelerinin sınırlı olmasıdır. Bu özellik lifli polimer donatılı elemanlarda gevrek davranışa neden olmakta ve yüksek dayanımlı betonarme eleman taşıma gücü kapasitesine ulaştığ anda aniden kırılmaktadır. Bunun yansıra lifli polimer donatıların eksenel rijitliğinin (EA) ve beton ile aderansının çelik donatılara kıyasla daha düşük olması elemanların servis yükleri altındaki deformasyon ve çatlak genişliklerinin yüksek değerler almasına neden olmaktadır. Bu sebeplerle lifli polimer donatılı betonarme elemanların sünekliliğini iyileştirmek ve eğilme performansını geliştirmek üzere çeşitli yaklaşımlara dayalı çalışmalar yapılmaktadır. Kesitte FRP donatının yanı sıra çeliğin de kullanılması literatürde önerilen yaklaşımlardan birisi olup bu konu üzerinde yapılan araştırmalar güncelliğini korumaktadır.

Literatüre göre çekme bölgesinde FRP ve çelik donatıların bir arada kullanıldığı hibrit donatılı kesite sahip betonarme elemanlar, deformasyon, çatlama davranışı ve taşıma gücü kapasitesi gibi kriterler dikkate alındığında sadece lifli polimer donatılı elemanlara kıyasla çok daha iyi performans sergilemektedirler.

$\mathrm{Bu}$ çalışmada, çekme bölgesinde FRP ve çelik donatıların bir arada kullanıldığı hibrit donatılı basit mesnetli betonarme kirişlerin yük-deplasman davranışları irdelenmiştir. Literatürde test verileri mevcut olan hibrit donatılı (GFRP ve çelik) basit mesnetli 6 adet betonarme kiriş numunesi sayısal bir yönteme dayalı olarak analiz edilmiş ve kirişlerin yük-deplasman ilişkileri teorik olarak elde edilmiştir. Çalışmada, sayısal yönteme dayalı olarak yapılan analizlerden elde edilen sonuçlar ile test sonuçlarının uyumlu olduğu gözlenmiştir.

\section{2. ÖNCEKİ ÇALIŞMALAR}

Hibrit donatılı kesit yaklaşımında kesitteki çeliğin sünek yapısı sayesinde FRP donatının neden olabileceği gevrek davranışı dengeleyerek elemanda istenilen sünek davranışın elde edilmesine çalışılmaktadır.

ACI440.1R-15 [1] standardında FRP donatılı betonarme kirişler için denge üstü tasarım önerilmekte, göçme anında FRP donatılar kopmadan önce kesitin basınç bölgesinde betonun ezilmede deformasyon sınırına ulaşmış olması beklenmektedir. $\mathrm{Bu}$ durumda elemanın sünekliği betonun özelliğine bağlı olacağından, betonun dayanımını artırmak elemanda süneklik davranışını iyileştirebilecektir. Bu yaklaşımdan yola çıkarak FRP donatılı kiriş elemanların sünekliğini iyileştirmek amacıyla lifli beton kullanarak betonun dayanımını artırmak literatürde önerilen yöntemlerden birisidir.

Mazaheripour ve arkadaşları [2], yukarıda bahsedilen yaklaşımları birleştirerek yaptıkları çalışmada yüksek dayanımlı kendiliğinden sıkışan beton içerisine çelik lif eklemişler ve kesitte boyuna donatı olarak GFRP donatı ile birlikte çelik donatılar kullanmışlardır. Hazırladıkları 200 x 500 mm I kesitli $4000 \mathrm{~mm}$ boyundaki ve $3700 \mathrm{~mm}$ açıklıklı 10 adet basit kiriş numunesini 4 noktalı eğilme testine tabi tutmuşlardır. Bazı numunelerde GFRP ve çelik halatlara farklı seviyelerde öngerilme uygulamışlardır. Bu numunelerin eğilme altında deplasman ve çatlama davranışlarını belirlemek üzere önerdikleri teorik modelde, yeni bir dengeli donatı oranı ile birlikte, öngerilme etkisini, kesme çatlaklarının eleman eğriliğine etkisini ve beton içerisindeki çelik liflerin çatlama durumundaki etkisini dikkate alan bir etkili atalet momenti ( $\left.\mathrm{I}_{\mathrm{eff}}\right)$ modeli tanımlamışlardır. Çalışmalarında, önerdikleri modele dayalı olarak elde ettikleri analiz sonuçlarının deneysel sonuçlar ile uyumlu olduğunu, hazırladıkları hibrit kesitli kiriş numunelerinin eğilme yükü altında yükdeplasman davranışını belirleyebildiklerini 
göstermişlerdir. Ayrıca deformasyonlar göz önüne alındığında, denge altı donatı oranına sahip öngerilmeli hibrit donatılı kirişlerin performansında eğilme dayanımında düşüş olmaksızın iyileşme sağlayabildiklerini de göstermişlerdir.

El-Refai ve arkadaşları [3], 230 ve $300 \mathrm{~mm}$ dikdörtgen kesitli $3700 \mathrm{~mm}$ açıklıklı $4000 \mathrm{~mm}$ uzunluğundaki basit mesnetli 6 adet hibrit (GFRP ve çelik) donatılı betonarme kiriş ile 3 adet sadece GFRP donatılı kirişi 4 noktalı eğilme testine tabi tutmuşlar ve kirişlerin eğilme davranışlarını irdelemişlerdir. Denge üstü donatı oranına sahip olan hibrit donatılı kirişlerin dayanım ve süneklik açısından GFRP donatılı kirişlere oranla daha iyi performans sergilediğini gözlemlemişlerdir. Test sonuçlarına bağlı olarak, ACI-440.1R-15 [1] standardında verilen formüller yardımıyla çatlak genişliklerini belirlemek üzere yeni bir aderans katsayısı $\left(\mathrm{k}_{\mathrm{b}}\right)$ önermişlerdir. Çalışmalarında taşıma gücü kapasitesi, çatlak genişlikleri ve deplasman değerleri açısından deneysel sonuçlar ile teorik sonuçların uyumlu olduğunu göstermişlerdir.

Qin ve arkadaşları [4], üç boyutlu sonlu elemanlar modeli kullanarak, hibrit donatılı kirişlerde hibrit donatı oranının eğilme davranışına etkisini incelemişlerdir. Taşıma gücü kapasitesini ve süneklik performansını optimize etmek üzere hibrit donatı oranı için uygun bir aralık belirlemeye çalışmışlardır. Hibrit donatı oranını, FRP donatı alanının çelik donatı alanına oranı şeklinde tanımlayarak, elastik ötesi bölgede yüksek dayanımı yeterli süneklik ve rijitlik ile optimize etmek üzere bu oran için 1 ile 2,5 değer aralığını önermişlerdir. Yaptıkları analizlerde literatürde mevcut çalışmalarda test edilmiş olan basit mesnetli hibrit donatılı kiriş numunelerinden yararlanmışlardır.

Bencardino ve arkadaşları [5], çalışmalarında çelik donatılı, aramid lifli polimer donatılı, cam lifli polimer donatılı ve hibrit donatılı betonarme elemanların davranışını belirlemeye yönelik olarak iki boyutlu sonlu eleman modeli önermişlerdir. Yöntemin geçerliliğini incelemek üzere literatürde mevcut olan deneysel çalışmalara ait numunelerden yararlanmışlardır. 17 adet kiriş numunesinin analizini yaptıkları çalışmada, hibrit donatılı kesite sahip betonarme numunelerin davranıșlarını önerdikleri iki boyutlu sonlu eleman yöntemiyle belirleyebilmişlerdir. Özellikle düşük ve normal seviyede donatı oranına sahip elemanlarda daha başarılı sonuçlar almışlardır. Sayısal yöntemle öngörülen göçme modlarının test sonuçlarıyla uyumlu olduğunu gözlemlemişlerdir.

Kara ve arkadaşları [6], hibrit donatılı betonarme kirişlerde eğrilik, deplasman ve moment kapasitesini belirlemek üzere denge denklemleri ve uygunluk şartlarına dayalı olarak sayısal bir yöntem önermişlerdir. Önerdikleri deplasman hesabı sadece basit mesnetli kirişler için geçerli olmaktadır. Literatürde mevcut çalışmalarda test edilmiş olan 46 adet basit mesnetli hibrit donatılı kiriş numunelerini geliştirdikleri yöntem ile analiz yapmışlardır. Hibrit donatılı kiriş numunelerde FRP donatı olarak aramid, cam ve karbon lifli polimer donatılar kullanılmıştır. Önerdikleri yöntemin doğruluğunu değerlendirmek üzere yaptıkları karşılaştırmalarda analizlerden elde ettikleri sonuçların test sonuçları ile uyumlu olduğunu gözlemlemişlerdir.

Yinghao ve Yong [7], 150 x $250 \mathrm{~mm}$ dikdörtgen kesitli $1800 \mathrm{~mm}$ açıklıklı $2000 \mathrm{~mm}$ boyundaki 3 adet hibrit (GFRP ve çelik) donatılı ve 1 adet sadece GFRP donatılı basit mesnetli betonarme kirişi 4 noktalı eğilme testine tabi tutmuşlardır. Kesitteki donatı oranının aynı olup donatı düzeninin değişken tutulduğu çalışmada, çelik ve FRP donatılar tek sıra veya iki sıra halinde kesite yerleştirilmiştir. Taşıma gücünü ve göçme modunu belirlemeye yönelik teorik modellerin önerildiği çalışmada, kesitteki donatı yerleşim düzeninin hibrit donatılı kirişlerin taşıma gücü kapasitesi ve rijitliği üzerinde etkili olduğunu gözlemlemişlerdir. Çatlak genişliğini daha çok çelik donatının kontrol ettiğini ve kesitteki çelik donatının derinliği arttıkça çatlak genişliğinin azaldığını gözlemlemişlerdir.

Dündar ve arkadaşları [8], hibrit (FRP-çelik) donatılı betonarme sürekli kirişlerin analiz ve tasarımına yönelik sayısal bir yöntem önermiş ve bu yönteme dayalı olarak hibrit (FRP-çelik) donatılı betonarme sürekli kirişlerin eğilme yükü altında yük-deplasman ilişkisini belirleyebilen bir bilgisayar programı hazırlamışlardır. Önerilen 
sayısal yöntemin geçerliliğini belirlemek amacıyla hazırladıkları iki adet GFRP donatılı ve 6 adet hibrit (GFRP-çelik) donatılı betonarme iki açıklıklı sürekli kirişleri, yük-deplasman ilişkisini belirlemek üzere eğilme yükü altında teste tabi tutmuşlardır. Önerdikleri yöntemin doğruluğunu değerlendirmek üzere yaptıkları karşılaştırmalarda analizlerden elde ettikleri sonuçların test sonuçları ile uyumlu olduğunu gözlemlemişlerdir.

Hibrit donatılı betonarme kirişlerin eğilme performansının irdelenmesi konusunda literatürde sınırlı sayıda çalışma mevcut olup konu ile ilgili çalışmalar güncelliğini korumaktadır.

Bu çalışmada, hibrit donatılı (GFRP ve çelik) basit mesnetli betonarme kirişlerin yük-deplasman davranışı teorik olarak irdelenmiştir. Literatürde test verileri mevcut olan, çekme bölgesinde GFRP ve çelik donatıların bir arada kullanıldığı hibrit donatılı basit mesnetli 6 adet betonarme kiriş numunesi sayısal bir yönteme dayalı olarak analiz edilmiş ve kirişlerin yük-deplasman ilişkileri teorik olarak elde edilerek teorik ve deneysel sonuçlar karşılaştırılmıştır.

\section{MALZEME MODELLERİ SAYISAL YÖNTEM}

$\mathrm{Bu}$ çalışmada, hibrit (FRP ve çelik) donatılı betonarme yatay taşıyıcı sistemlerin yük-deplasman davranışını belirlemek üzere Dündar ve arkadaşları [8] tarafından geliştirilmiş olan bir bilgisayar programı kullanılmıştır. Program, dikdörtgen kesitli yatay taşıyıcı sistemleri üniform veya tekil yükler altında çözümleyebilmekte, kesitlerde bulunan çelik veya FRP donatısını bulundukları konuma göre çekme veya basınç donatısı olarak dikkate alabilmektedir. Çelik ve FRP donatılar kesitin çekme ve/veya basınç bölgesinde tek bir sırada veya iki farklı sırada tanımlanabilmektedir. Tanımlanan donatılara çekme ve basınç durumları için farklı elastisite modülü değerleri ve benzer şekilde farklı akma veya kopma dayanımı değerleri atanabilmektedir.

Programın dayandığı sayısal yöntemde, çatlamış durumda eleman rijitliklerinin hesaplanması için etkili atalet momentleri, moment-eğrilik ilişkilerinden elde edilmektedir. Sistem deplasmanlarının hesabında rijitlik matrisi yöntemi kullanılmaktadır. Analizin ilk adımında sistemdeki farklı donatıya sahip tüm kesitler için momenteğrilik ilişkileri kesitin taşıma gücü moment kapasitesi seviyesine kadar hesaplanmakta ve saklanmaktadır. Kiriş elemanının herhangi bir kesitindeki rijitliği, verilen yükleme ve mesnetlenme koşulları altında yapılan analizinden hesaplanan moment değerlerine karşılık gelen eğrilik dikkate alınarak elde edilebilmektedir. Elemanın herhangi bir kesitindeki etkili eğilme rijitliği Dündar ve arkadaşları [9] tarafindan geliştirilen Eşitlik 1'deki gibi ifade edilmektedir.

$\frac{1}{\mathrm{E}_{\mathrm{c}} \mathrm{I}_{\mathrm{eff}}}=\frac{1}{\mathrm{E}_{\mathrm{c}} \mathrm{I}_{\mathrm{cr}}}\left[1-\left(1-\frac{\varphi_{\mathrm{M}}}{\mathrm{M}}\right) \mathrm{E}_{\mathrm{c}} \mathrm{I}_{\mathrm{cr}}\right] \leq \frac{1}{\mathrm{E}_{\mathrm{c}} \mathrm{I}_{\mathrm{g}}}$

Eşitlik 1'de $E_{c}$ betonun elastisite modülünü, $I_{\text {eff }}$ etkili atalet momentini, $I_{c r}$ çatlamış kesit atalet momentini, $I_{g}$ brüt beton kesit atalet momentini, $M$ eğilme momentini ve $\varphi_{M}$ eğriliği göstermektedir.

Bu çalışmada eleman rijitlik matrisini elde etmek ve herhangi bir kesitteki deplasmanı hesaplamak üzere literatürdeki mevcut yarı ampirik etkili rijitlik modelleri yerine Eşitlik 1 kullanılmaktadır. Daha sonra dış yükler altında sistemin lineer elastik analizi yapılmaktadır. Bu analiz sonucu elde edilen eleman uç kuvvetleri kullanılarak elemanlarda çatlamış ve çatlamamış bölgeler belirlenmekte ve her bölgenin eleman rijitliğine katkısı daha önce belirlenmiş olan moment-eğrilik ilişkileri de kullanılarak sayısal integrasyon tekniği ile hesaplanmaktadır.

Programda elemanlara ait efektif rijitlikler, çatlamış kesit analizi ile hesaplanan moment-eğrilik ilişkisinden elde edilmektedir. Bu şekilde eleman rijitlikleri belirlendikten sonra sistem rijitlik matrisi oluşturularak çözüme gidilmekte, düğüm deplasmanları ve eleman uç kuvvetleri hesaplanmaktadir. Programa tanitılan yakınsama kriteri sağlanıncaya kadar uç kuvvetleri hesaplama işlemine devam edilmektedir.

Çalışmada, beton basınç bölgesinde gerilme-şekil değiştirme ilişkisi için CEB-FIB [10] ve Hognestad 
modelleri kullanılmış olup çalışmada sadece CEB-FIB modeli kullanılarak elde edilen grafiklere yer verilmiştir. Şekil 1'de verilen ve Eşitlik 2'de tanımlanan CEB-FIB modeli ile Şekil 2'de verilen ve Eşitlik 3'te tanımlanan Hognestad modelinde $\varepsilon_{\mathrm{co}}=0,002, \varepsilon_{\mathrm{cu}}=0,003$ alınmıştır.

Eşitlik 2 ve 3 'te $f_{c}$ ve $\varepsilon_{c}$ sirasıyla betonun basınç gerilmesini ve beton basınç lifindeki birim kısalmayı, $\mathrm{f}_{\mathrm{c}}$ betonun silindir basınç dayanımını, $\varepsilon_{\mathrm{co}}$ ve $\varepsilon_{\mathrm{cu}}$ sirasiyla betonda maksimum gerilmeye karşılık gelen birim kısalmayı ve kırılma anındaki birim kısalmayı göstermektedir.

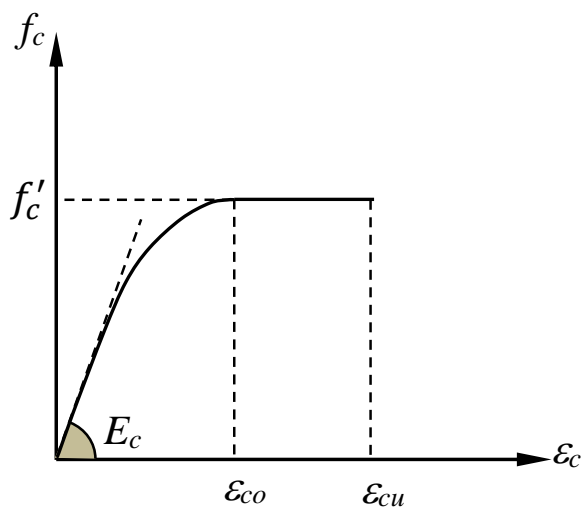

Şekil 1. Beton basınç bölgesinde gerilme-şekil değiştirme için CEB-FIB modeli

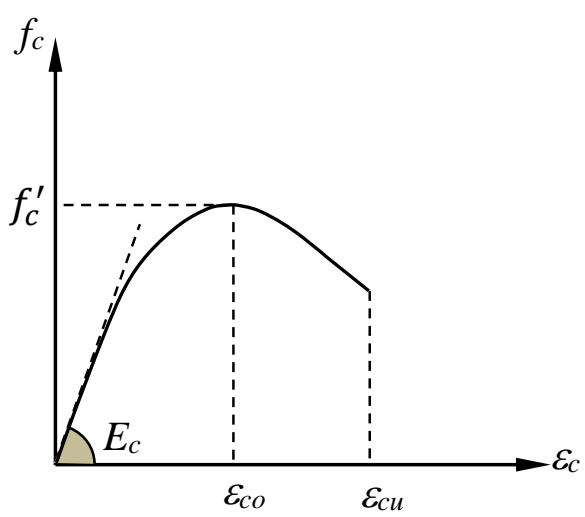

Şekil 2. Beton basınç bölgesinde gerilme-şekil değiştirme için Hognestad modeli

$\mathrm{f}_{\mathrm{c}}=\mathrm{f}_{\mathrm{c}}^{\prime}\left[\frac{2 \varepsilon_{\mathrm{c}}}{\varepsilon_{\mathrm{co}}}-\left(\frac{\varepsilon_{\mathrm{c}}}{\varepsilon_{\mathrm{co}}}\right)^{2}\right] \quad \varepsilon_{\mathrm{c}} \leq \varepsilon_{\mathrm{co}}$

$$
\begin{aligned}
& \mathrm{f}_{\mathrm{c}}=\mathrm{f}_{\mathrm{c}}^{\prime} \quad \varepsilon_{\mathrm{co}} \leq \varepsilon_{\mathrm{c}} \leq \varepsilon_{\mathrm{cu}} \\
& \mathrm{f}_{\mathrm{c}}=\mathrm{f}_{\mathrm{c}}^{\prime}\left[\frac{2 \varepsilon_{\mathrm{c}}}{\varepsilon_{\mathrm{co}}}-\left(\frac{\varepsilon_{\mathrm{c}}}{\varepsilon_{\mathrm{co}}}\right)^{2}\right] \quad \varepsilon_{\mathrm{c}} \leq \varepsilon_{\mathrm{cu}} \\
& \mathrm{f}_{\mathrm{c}}=\mathrm{f}_{\mathrm{c}}^{\prime} \quad \varepsilon_{\mathrm{co}} \leq \varepsilon_{\mathrm{c}} \leq \varepsilon_{\mathrm{cu}}
\end{aligned}
$$

Çalışmada, betonun çekmede gerilme-birim deformasyon ilişkisi olarak Şekil 3'te verilen iki bölgeli doğrusal çekme rijitleşmesi modeli esas alınmıştır. Eşitlik 4'te tanımlanan modelde $E_{c}$ betonun elastisite modülünü, $f_{r}$ betonun çatlama gerilmesini, $f_{t}$ betonun çekme gerilmesini, $\varepsilon_{t}$ beton çekme birim deformasyonunu, $\varepsilon_{c t u}$ kırılma anındaki birim deformasyonu, $\varepsilon_{c r}$ çatlama anındaki birim deformasyonu göstermektedir. $\alpha_{t s}$ ise çekme rijitleşmesi parametresini göstermekte olup literatürde 2 ile 25 arasında değer alınması önerilmektedir [11]. $\mathrm{Bu}$ çalışmada çekme rijitleşmesi parametresi $\alpha_{t s}=2$ alınmıştır.

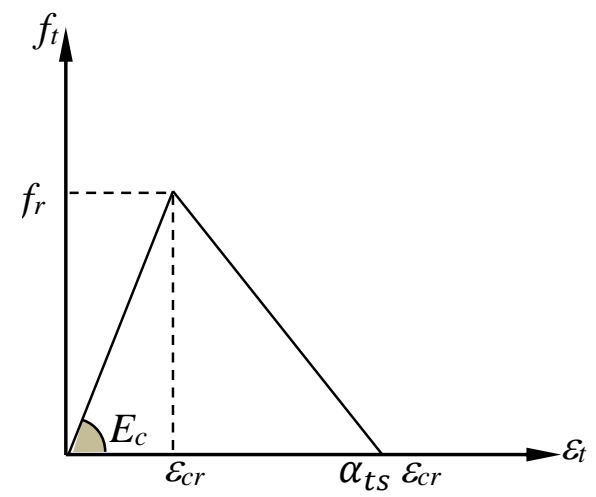

Şekil 3. İki bölgeli doğrusal çekme rijitleşmesi modeli

$$
\begin{aligned}
& \mathrm{f}_{\mathrm{t}}=\mathrm{E}_{\mathrm{c}} \varepsilon_{\mathrm{t}} \quad \varepsilon_{\mathrm{t}} \leq \varepsilon_{\mathrm{cr}} \\
& \mathrm{f}_{\mathrm{t}}=\mathrm{f}_{\mathrm{r}}-\frac{\mathrm{f}_{\mathrm{r}}}{\varepsilon_{\mathrm{ctu}}-\varepsilon_{\mathrm{cr}}}\left(\varepsilon_{\mathrm{t}}-\varepsilon_{\mathrm{cr}}\right), \\
& \varepsilon_{\mathrm{ctu}} \geq \varepsilon_{\mathrm{t}} \geq \varepsilon_{\mathrm{cr}} \\
& \varepsilon_{\mathrm{ctu}}=\alpha_{\mathrm{ts}} \varepsilon_{\mathrm{cr}}
\end{aligned}
$$

FRP donatıların gerilme-şekil değiştirme ilişkisi Şekil 4'te de görüldüğü gibi kopma anına kadar lineer elastik alınmış ve Eşitlik 5 ile tanımlanmıştır. 
Eşitlik 5'te $f_{f}$ ve $\varepsilon_{f}$ sırasıyla FRP donatısındaki gerilme ve şekil değiştirmeyi; $E_{f}$ FRP donatısının elastisite modülünü ve $\varepsilon_{f u}$ kopma anındaki şekil değiştirmesini göstermektedir.

$$
\mathrm{f}_{\mathrm{f}}=\mathrm{E}_{\mathrm{f}} \varepsilon_{\mathrm{f}} \quad \varepsilon_{\mathrm{f}} \leq \varepsilon_{\mathrm{fu}}
$$

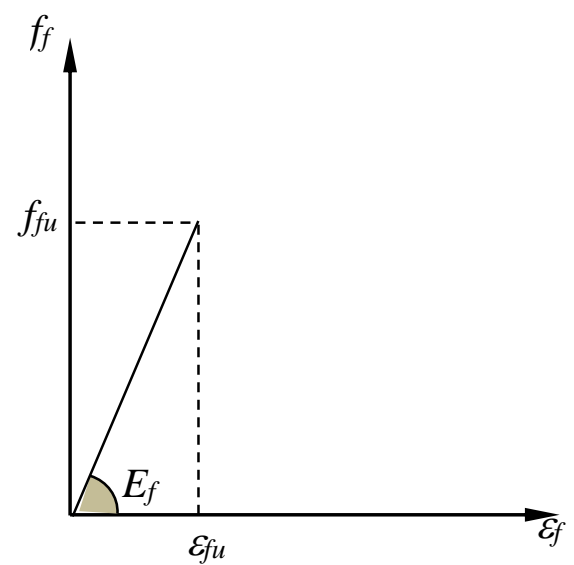

Şekil 4. FRP donatısının gerilme-şekil değiştirme ilişkisi

Çeliğin gerilme-şekil değiştirme ilişkisi için, Şekil 5 'te verilen ve Eșitlik 6 ile tanımlanan elastoplastik malzeme modeli kullanılmıştır.

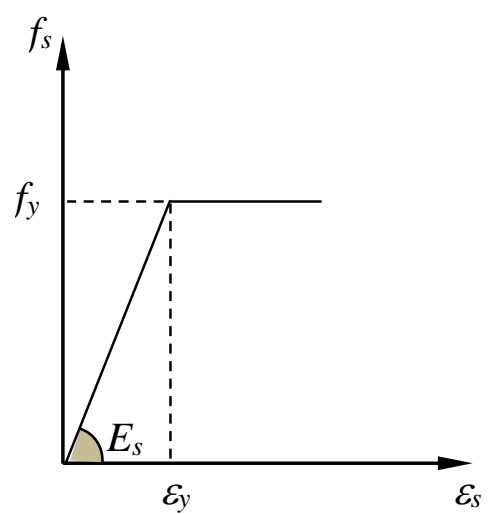

Şekil 5. Çeliğin gerilme-şekil değiştirme ilişkisi

$$
f_{s}=E_{s} \varepsilon_{s} \leq f_{y}
$$

Eşitlik 6'da $f_{s}$ and $\varepsilon_{s}$ sırasıyla çeliğin gerilme ve şekil değiştirmesini, $E_{s}$ ve $f_{y}$ ise çeliğin elastisite modülü ve akma gerilmesini göstermektedir.

\section{HİBRIT DONATILI BETONARME KİRISSLERDE MOMENT-EĞRILIIK ILIŞSKISI}

Betonarme yapılar, içerisinde bulunan çelik donatılarının korozyona uğraması nedeniyle yıpranmakta ve zamanla hasar görmektedir. Çelik yapılarda da taşıyıcı sistemi teşkil eden yapısal çelik elemanlar korozyona maruz kalmakta ve zamanla oluşan hasar nedeniyle bu yapılarda önemli derecede yapısal onarıma ihtiyaç duyulabilmektedir. Yeni ve mevcut yapiların kullanım ömürlerini arttırmak ve ekonomik ömürleri boyunca gerekli olacak bakım ve onarım maliyetlerini azaltmak amacı ile yaklaşık son 15 yıldır lifli polimer malzemeler (FRP) inşaat uygulamalarında kullanılmaya başlanmıştır. Hibrit donatılı betonarme kiriş kesitlerinde çekme bölgesinde çelik donatılar korozyon etkilerinden korunmak amacıyla yüzeye yakın yerleştirilirken FRP donatılar daha büyük paspayı değerleriyle tarafsız eksene daha yakın yerleştirilebilmektedir.

$\mathrm{Bu}$ çalışmada yapılan analizler için kullanılan sayısal yöntemde, çelik ve FRP donatılar kesitin çekme ve/veya basınç bölgesinde tek bir sırada veya iki farklı sırada tanımlanabilmektedir. Tanımlanan donatılara çekme ve basınç durumları için farklı elastisite modülü değerleri ve benzer şekilde farklı akma veya kopma dayanımı değerleri atanabilmektedir. Hibrit (FRP ve çelik) donatılı betonarme kiriş kesitine ait birim deformasyon ve buna karşılık gelen gerilme dağılımı çekme ve basınç bölgesinde iki farklı donatı sırası esas alınarak Şekil 6'da gösterilmektedir.

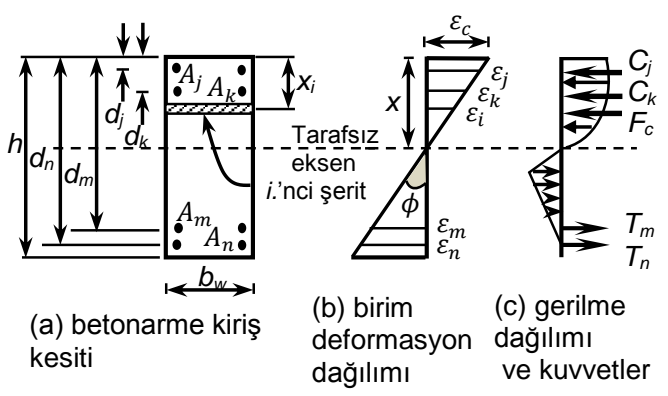

Şekil 6. Dikdörtgen kesitte birim deformasyon, gerilme dağılımı ve kuvvetler 
Sayısal yöntemde, çatlamış durumda eleman rijitliklerinin hesaplanması için etkili atalet momentleri, moment-eğrilik ilişkilerinden elde edilmektedir. Hibrit donatılı betonarme kiriş kesitlerine ait moment-eğrilik ilişkilerinin hesaplanabilmesi için tarafsız eksen üzerinde kalan beton basınç bölgesi $\left(\varepsilon_{\mathrm{cmax}}\right) \mathrm{n}$ adet şeride bölünmektedir. Her bir şeride karş1lık gelen moment-eğrilik değerini belirlemek üzere tarafsız eksen derinliği (x) için bir başlangıç değeri belirlenmekte, denge denklemleri ve uygunluk şartı sağlanıncaya kadar iterasyonlara devam edilerek ilgili şeritteki tarafsız eksen derinliğine karşılık gelen $\left(\varepsilon_{\mathrm{c}}\right)$ değeri hesaplanmaktadır. Böylece her $\left(\varepsilon_{\mathrm{c}}\right)$ değeri için yeni bir moment-eğrilik değeri hesaplanmaktadır. Beton basınç bölgesinde en diş lifte maksimum birim kısalmaya ulaşılıncaya kadar moment-eğrilik ilişkileri hesaplanmaya devam edilmektedir. Düzlem kesitlerin eğilmeden sonra da düzlem kalacağı kabulü ve donatı ile beton arasındaki aderansın tam olduğu varsayımı yapılarak (i) şerit numarası olmak üzere betonda $i$ şeridindeki birim deformasyon Eşitlik 7a'daki gibi ifade edilmektedir.

$$
\varepsilon_{\mathrm{i}}=\frac{\mathrm{X}-\mathrm{x}_{\mathrm{i}}}{\mathrm{X}} \varepsilon_{\mathrm{c}}
$$

basınç bölgesinde FRP ve/veya çelikteki birim deformasyon:

$$
\varepsilon_{\mathrm{j}} \text { veya } \varepsilon_{\mathrm{k}}=\frac{\mathrm{x}-\left(\mathrm{d}_{\mathrm{j}} \text { veya } \mathrm{d}_{\mathrm{k}}\right)}{\mathrm{x}} \varepsilon_{\mathrm{c}}
$$

çekme bölgesinde FRP ve/veya çelikteki birim deformasyon:

$$
\varepsilon_{\mathrm{m}} \text { veya } \varepsilon_{\mathrm{n}}=\frac{\mathrm{x}-\left(\mathrm{d}_{\mathrm{m}} \text { veya } \mathrm{d}_{\mathrm{n}}\right)}{\mathrm{x}} \varepsilon_{\mathrm{c}}
$$

$\varepsilon_{c}$ beton basınç bölgesinde en diş lifteki birim kısalma; $\varepsilon_{i} i$ 'nci şeridin merkezinde beton basınç veya çekme birim deformasyonu; $\varepsilon_{j}$ ve $\varepsilon_{k}$ basınç bölgesinde j'nci ve k'ncı sıradaki donatıların birim deformasyonu; $\varepsilon_{m}$ ve $\varepsilon_{n}$ çekme bölgesinde $m$ 'nci ve $n$ 'nci sıradaki donatıların birim deformasyonu; $d_{j}$ ve $d_{k}$ basınç bölgesinde j'nci ve $k$ 'ncı sıradaki donatıların derinliğini; $d_{m}$ ve $d_{n}$ çekme bölgesinde $m$ 'nci ve n'nci sıradaki donatıların derinliğini göstermektedir.

Şekil 6 ve denge denklemleri dikkate alınarak aşağıdaki şekilde Eşitlik 8 yazılabilmektedir.

$$
\sum F=F_{c}+\left(C_{j} \text { ve } C_{k}\right)-\left(T_{m} \text { ve } T_{n}\right)=0
$$

$F_{c}$ beton basınç kuvveti; $C_{j}$ ve $C_{k}$ sırasıyla $j$ 'nci ve $k$ 'ncı sıradaki FRP ve/veya çelik donatılardaki basınç kuvvetini; $T_{m}$ ve $T_{n}$ sırasıyla $m$ 'nci ve $n$ 'nci sıradaki FRP veya çelik donatılardaki çekme kuvvetini göstermektedir. $\mathrm{Bu}$ kuvvetler Eşitlik 9'da gösterilmektedir.

$\mathrm{F}_{\mathrm{c}}=\sum_{\mathrm{i}=1}^{\mathrm{n}} \mathrm{f}_{\mathrm{ci}} \mathrm{h}_{\mathrm{i}} \mathrm{b}_{\mathrm{w}}$

$\mathrm{C}_{\mathrm{j}}=\mathrm{A}_{\mathrm{j}} \mathrm{E}_{\mathrm{j}} \varepsilon_{\mathrm{j}} \quad \mathrm{C}_{\mathrm{k}}=\mathrm{A}_{\mathrm{k}} \mathrm{E}_{\mathrm{k}} \varepsilon_{\mathrm{k}}$

$\mathrm{T}_{\mathrm{m}}=\mathrm{A}_{\mathrm{m}} \mathrm{E}_{\mathrm{m}} \varepsilon_{\mathrm{m}} \quad \mathrm{T}_{\mathrm{n}}=\mathrm{A}_{\mathrm{n}} \mathrm{E}_{\mathrm{n}} \varepsilon_{\mathrm{n}}$

$f_{\text {ci }}$ i’inci şeritteki beton basınç veya çekme gerilmesini; $h_{i} i$ 'nci şerit yüksekliğini; $b_{w}$ kiriş kesit genişliğini; $A_{j}$ ve $A_{k}$ basınç bölgesinde $j$ 'nci ve $k$ 'ncı sıradaki çelik ve/veya FRP donatı alanını; $A_{m}$ ve $A_{\mathrm{n}}$ çekme bölgesinde $m$ 'nci ve $n$ 'nci sıradaki çelik ve/veya FRP donatı alanını; $E_{j}$ ve $E_{k}$ basınç bölgesinde j'nci ve k'ncı sıradaki çelik ve/veya FRP donatıların elastisite modülünü; $E_{m}$ ve $E_{n}$ çekme bölgesinde $m$ 'nci ve $n$ 'nci sıradaki çelik ve/veya FRP donatıların elastisite modülünü; $\varepsilon_{\mathrm{m}}$ ve $\varepsilon_{\mathrm{n}}$ çekme bölgesinde $m$ 'nci ve n'nci sıradaki çelik ve/veya FRP donatıların birim deformasyonunu göstermektedir.

Tarafsız eksen derinliği Eşitlik 9'da verilen ifadeler dikkate alınmak suretiyle yeterli yakınsama kriteri sağlanacak şekilde iteratif olarak belirlenmektedir. Yakınsama kriteri $\epsilon$ için bu çalışmada $1 \times 10^{-8}$ değeri esas alınmıştır Eşitlik 10.

$$
\begin{aligned}
& \frac{\left|\sum \mathrm{F}\right|}{\left|\mathrm{F}_{\mathrm{c}}\right|} \leq \epsilon \\
& \left|\frac{\mathrm{P}_{\mathrm{i}}^{\mathrm{n}}-\mathrm{P}_{\mathrm{i}}^{\mathrm{n}-1}}{\mathrm{P}_{\mathrm{i}}^{\mathrm{n}}}\right| \leq \epsilon
\end{aligned}
$$


$n$ iterasyon numarası ve $P_{i}^{n}(\mathrm{i}=1-6)$ 'nci iterasyon için sistemdeki her bir elemanın uç kuvvetidir. Beton basınç lifindeki maksimum birim kısalma için moment-eğrilik ifadeleri Eşitlik 11'de verilen şekilde hesaplanmaktadır.

$$
\begin{aligned}
& \phi_{\mathrm{M}}=\frac{\varepsilon_{\mathrm{c}}}{\mathrm{x}} \\
& M=\sum_{i=1}^{n} \begin{array}{l}
{\left[F_{c i}\left(x-x_{i}\right)+\left(T_{m}\right)\left(x-d_{m}\right)+\right.} \\
\left(T_{n}\right)\left(x-d_{n}\right)+\left(C_{j}\right)\left(x-d_{j}\right)+
\end{array}
\end{aligned}
$$

$F_{c i}$ i'nci şeridin merkezinde beton basınç veya çekme kuvvetidir.

$\mathrm{Bu}$ yaklaşımla her bir kiriş kesiti için momenteğrilik ilişkisi elde edilmektedir. Çatlamış kesit analizinden elde edilen bu moment-eğrilik ilişkileri, sisteme etkiyen dış yükler etkisinde elemanların çatlaması durumunda elemanların etkili atalet momentlerinin hesabı için esas teşkil etmektedir.

$\mathrm{Bu}$ çalışmada, hibrit donatılı betonarme kirişlerin yük-deplasman davranışlarını irdelemek üzere, literatürde El-Refai ve arkadaşları [3], tarafından sunulmuş olan deneysel çalışmada testleri yapılmış 6 adet hibrit donatılı (GFRP ve çelik) basit mesnetli betonarme kiriş numunesi esas alınmıştır. Kirişler sayısal yöntemle çözümlenerek yük-deplasman eğrileri teorik olarak elde edilmiş ve sonuçlar mevcut test sonuçlarıyla karşılaştırılmıştır. El-Refai ve arkadaşları [3], tarafindan sunulmuş olan deneysel çalışmadaki kirişlerde kullanılan çelik donatıların akma dayanımı $520 \mathrm{MPa}$ olup lifli polimer donatı olarak elastisite modülü $50 \mathrm{GPa}$ ve kopma dayanımı $1000 \mathrm{MPa}$ olan GFRP donatılar kullanılmıştır. Donatılar kesitte tek sıra halinde düzenlenmiștir. Kiriş örnekleri için kullanılan betonun ortalama silindir basınç dayanımı $40 \mathrm{MPa}$ olarak belirtilmiştir. Kirişler 230 x 300 mm dikdörtgen kesitli ve $4000 \mathrm{~mm}$ uzunluğunda olup kesit ve donatı detayları Çizelge 1 ve Şekil 7'de verilmiştir. Numuneler $3700 \mathrm{~mm}$ açıklıklı test düzeneğinde dört noktalı eğilme testine tabi tutulmuş ve simetrik olarak yüklenen iki adet tekil yükün arasındaki mesafe $1200 \mathrm{~mm}$ olarak tasarlanmıştır. Kiriş örneklerine ait donatı detayları
Çizelge 1'de verilmektedir. Deney sürekli kirişlerinin mesnetlenme ve yükleme durumu Şekil 7'de görülmektedir. Kirişlere ait donatı detayları ve mekanik özellikleri Çizelge 1'de verilmektedir.

\begin{tabular}{|c|c|c|c|}
\hline Numune İsmi & Donatı Yeri & $\begin{array}{c}\text { Donatı } \\
\text { Miktarı }\end{array}$ & $\begin{array}{c}\text { Donatı } \\
\text { Cinsi }\end{array}$ \\
\hline \multirow{3}{*}{$2 \mathrm{G} 12-1 \mathrm{~S} 10$} & Üst & $2 \emptyset 8$ & Çelik \\
\hline & Alt & $1 \emptyset 10$ & Çelik \\
\hline & Alt & $2 \varnothing 12$ & GFRP \\
\hline \multirow{3}{*}{$2 \mathrm{G} 12-2 \mathrm{~S} 10$} & Üst & $2 \varnothing 8$ & Çelik \\
\hline & Alt & $2 \varnothing 10$ & Çelik \\
\hline & Alt & $2 \varnothing 12$ & GFRP \\
\hline \multirow{3}{*}{$2 \mathrm{G} 12-2 \mathrm{~S} 12$} & Üst & $2 \varnothing 8$ & Çelik \\
\hline & Alt & $2 \emptyset 12$ & Çelik \\
\hline & Alt & $2 \emptyset 12$ & GFRP \\
\hline \multirow{3}{*}{$2 \mathrm{G} 16-2 \mathrm{~S} 10$} & Üst & $2 \varnothing 8$ & Çelik \\
\hline & Alt & $2 \varnothing 10$ & Çelik \\
\hline & Alt & $2 \emptyset 16$ & GFRP \\
\hline \multirow{3}{*}{$2 \mathrm{G} 16-2 \mathrm{~S} 12$} & Üst & $2 \varnothing 8$ & Çelik \\
\hline & Alt & $2 \varnothing 12$ & Çelik \\
\hline & Alt & $2 \emptyset 16$ & GFRP \\
\hline \multirow{3}{*}{$2 \mathrm{G} 16-2 \mathrm{~S} 16$} & Üst & $2 \varnothing 8$ & Çelik \\
\hline & Alt & $2 \emptyset 16$ & Çelik \\
\hline & Alt & $2 \emptyset 16$ & GFRP \\
\hline
\end{tabular}

Çizelge 1. Basit mesnetli kirişlerin donatı detayları

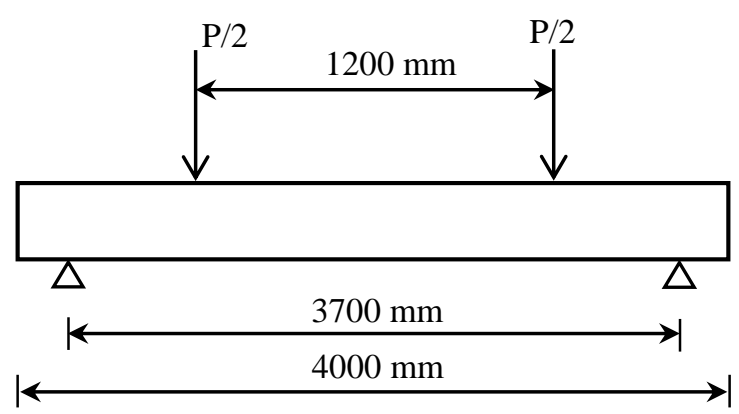

Şekil 7. Basit kiriş ve yükleme durumu 


\section{ARAŞTIRMA BULGULARI VE TARTIŞMA}

Literatürde El-Refai ve arkadaşları [3], tarafından sunulmuş olan deneysel çalışmada test verileri mevcut 6 adet hibrit donatılı (GFRP ve çelik) basit mesnetli betonarme kirişlerin analiz edilmesi sonucunda her bir kirişe ait yük-deplasman eğrisi elde edilmiştir. Analiz sonuçları, Şekil 7-12'deki grafiklerde, mevcut deneysel çalışmalarda verilmiş olan kiriş numunelerine ait yük-deplasman ilişkileriyle karşılaştırılmaktadır.

Şekil 8-13'de yük-deplasman eğrileri verilen kirişler denge üstü donatı oranıyla tasarlanmış olup kirişlerin $\rho$ eff (efektif donatı) / $\rho f b$ (dengeli donatı) oranları literatürdeki çalışmada sırasıyla 1,04,1,121,36-1,74-1,96 ve 2,32 olarak verilmiştir. Tüm kirişler hibrit donatılı olup yük-deplasman eğrilerinin üç kısımdan oluştuğu gözlenmektedir. İlk kısım yükleme anında başlayıp kirişte çatlama anına kadar devam etmektedir. Kirişte çatlama ile başlayan ikinci kısmın azalan eğimi çatlamadan dolayı eleman rijitliğindeki düşüşü ve bunun sonucu olarak gerçekleşen deplasman artışını ifade etmektedir. Çelik donatıların akmasıyla başlayan ve non-lineer davranışın görüldüğü üçüncü kısım göçme anına kadar devam etmektedir. Grafiklerde, her üç kısım için teorik olarak elde edilen yükdeplasman eğrileri ile mevcut test sonuçlarını gösteren eğriler arasında iyi derecede uyum sağlandığı gözlenmektedir.

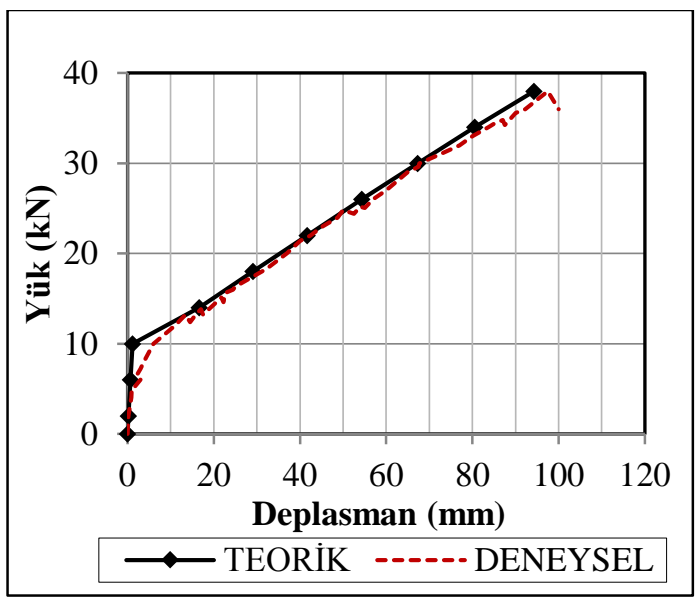

Şekil 8. 2G12-1S10 kirişi yük-deplasman ilişkisi

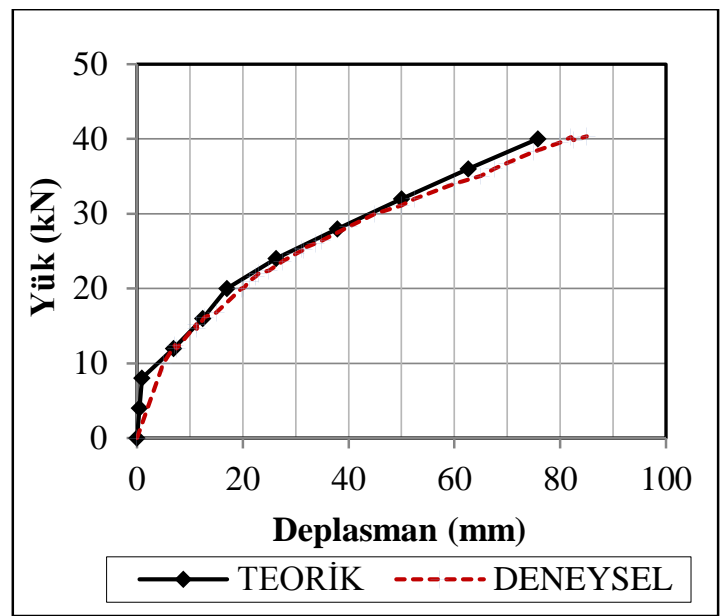

Şekil 9. 2G12-2S10 kirişi yük-deplasman ilişkisi

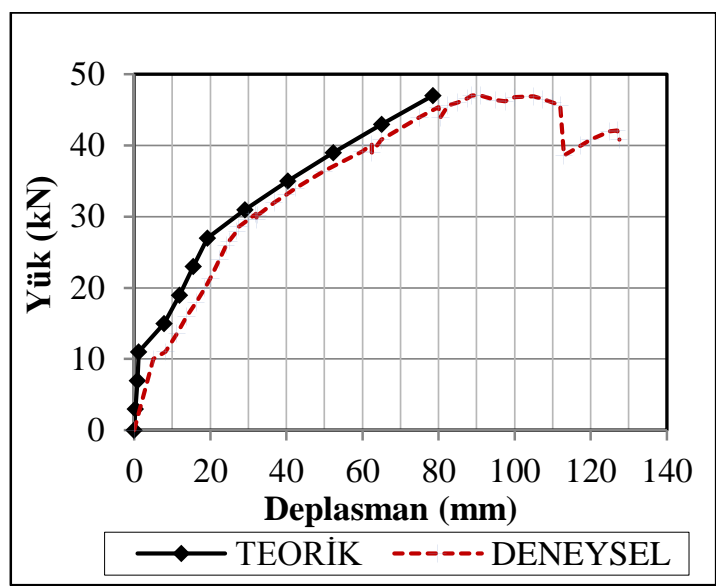

Şekil 10. 2G12-2S12 kirişi yük-deplasman ilişkisi

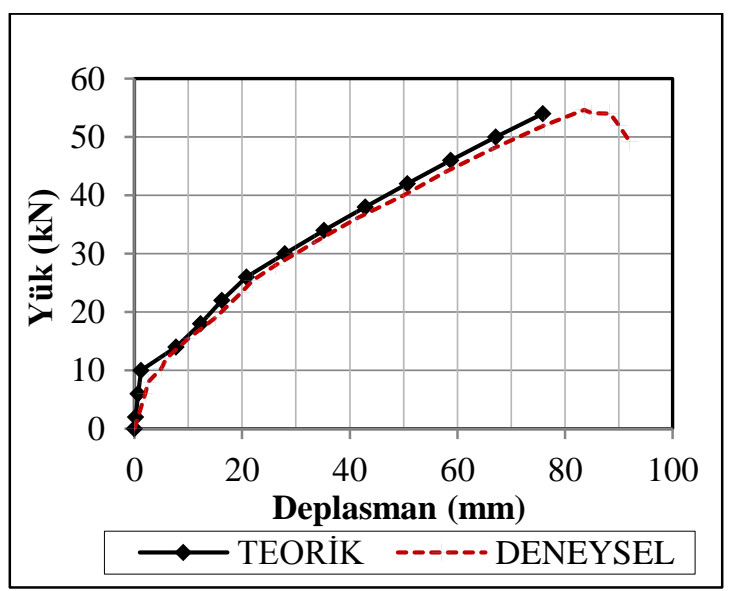

Şekil 11. 2G16-2S10 kirişi yük-deplasman ilişkisi 


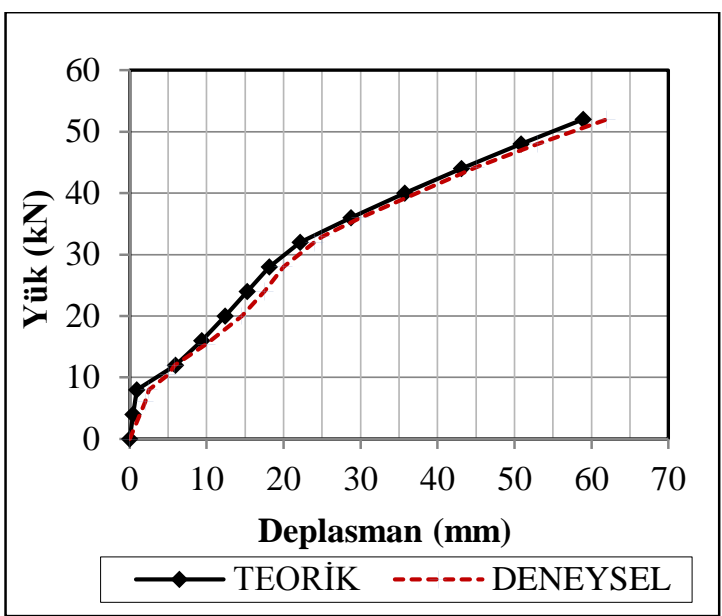

Şekil 12. 2G16-2S12 kirişi yük-deplasman ilişsisi

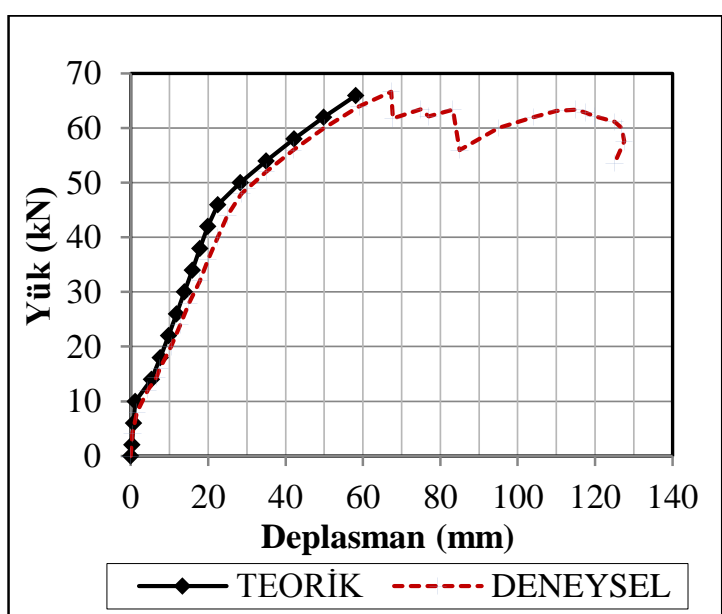

Şekil 13. 2G16-2S16 kirişi yük-deplasman ilişkisi

Yük-deplasman eğrileri elde edilirken hesaplamalarda, CEB-FIB ve Hognestad modellerinin her ikisi de kullanılmıştır. Her iki model esas alınarak elde edilen deplasmanlar arasındaki farklılıklar, sadece üçüncü kısımda yüklemenin son aşamalarında ortaya çıkmış olup $\% 0,5$ değerinin altında kaldığından çalışmada sadece CEB-FIB modeli kullanılarak elde edilen grafiklere yer verilmiştir (Şekil 8-13).

Mevcut deneysel çalışmada, denge üstü olarak tasarlanmış olan hibrit donatılı kirişlerin göçme biçimlerinin çelik donatının akmasının ardından betonun ezilmesi șeklinde gerçekleștiği, GFRP donatıların kopmadığ kirişinde ise çelik donatının akması ile betonda ezilme ve GFRP donatının kopmasının aynı anda gerçekleştĭgi bildirilmiş̧tir.

Şekil 8-13'te gerek göçme anında gerekse servis yükleri seviyesinde teorik ve test sonuçlarının oldukça yakın değerler aldığı gözlenmektedir. Servis yükü seviyesi olarak kabul edilebilecek olan ve taşıma gücünün \%40'ına karşıllk gelen yük seviyesindeki düşey deplasmanların teorik değerleri ve test sonuçları Çizelge 2'de verilmiştir.

Çizelge 2. Taşıma gücünün $\% 40$ 'ına karşılık gelen yük seviyesinde kiriş açıklık ortalarında elde edilen düşey deplasman değerleri

\begin{tabular}{|c|c|c|c|c|}
\hline \multirow{2}{*}{ Kiriş ismi } & $\begin{array}{c}\text { Taşıma } \\
\text { gücü yük } \\
\text { düzeyinin } \\
\text { \%40’1 }(\mathrm{kN})\end{array}$ & \multicolumn{2}{|c|}{$\begin{array}{c}\text { Açıklık ortas1 } \\
\text { düşey deplasman } \\
\text { değerleri }(\mathrm{mm})\end{array}$} & $\begin{array}{c}\text { Teorik } \\
\text { / Test }\end{array}$ \\
\hline 2G12-1S10 & 15,24 & 21,21 & 22,47 & 0,944 \\
\hline 2G12-2S10 & 17,13 & 14,65 & 15,49 & 0,946 \\
\hline 2G12-2S12 & 18,86 & 13,01 & 17,47 & 0,745 \\
\hline 2G16-2S10 & 21,84 & 16,88 & 18,18 & 0,929 \\
\hline 2G16-2S12 & 20,67 & 12,90 & 15,08 & 0,855 \\
\hline 2G16-2S16 & 26,72 & 12,17 & 14,30 & 0,851 \\
\hline
\end{tabular}

Çizelge 2'de, servis yüküne karş1lık gelen teorik ve deneysel olarak elde edilen deplasman değerleri oranının yaklaşık $\% 90$ seviyelerinde olduğu gözlenmektedir.

\section{SONUÇLAR}

$\mathrm{Bu}$ çalışmada, çekme bölgesinde FRP ve çelik donatıların bir arada kullanıldığı hibrit donatılı betonarme kirişlerin yük-deplasman davranış1 irdelenmiştir. $\mathrm{Bu}$ amaçla, literatürde test verileri mevcut [3] olan 6 adet hibrit donatıll (GFRP ve çelik) basit mesnetli betonarme kiriş esas alınmış, kirişler sayısal yöntemle analiz edilmiş ve yükdeplasman eğrileri teorik olarak elde edilmiştir. Sonuçlar literatürdeki mevcut test sonuçlarıyla karşılaştırılmıştır. Çalışmada, teorik olarak elde edilen yük-deplasman ilişkileri ile mevcut test sonuçlarını gösteren eğriler arasında iyi derecede uyum sağlandığı gözlenmektedir. Sayısal yöntemde 
kirişlerin çatlamış durumdaki efektif rijitliklerinin hesabında çatlamış kesit analizi ile hesaplanan moment-eğrilik ilişkileri esas alınmaktadır. $\mathrm{Bu}$ yaklaşımla, çekme bölgesinde çok farklı mekanik özelliklere sahip donatılar (GFRP, BFRP, AFRP, CFRP, Steel vb.) içeren hibrit donatılı betonarme kirişlerin eğilme yükü altındaki yük-deplasman davranışları yükleme başlangıcından göçme anına kadar tüm aşamalar için belirlenebilmektedir. Çalışmada kullanılan sayısal yöntemin hibrit donatılı basit mesnetli betonarme kirişlerin göçme anına kadar olan eğilme davranışlarını belirlemeye yönelik faydalı bir yöntem olduğu anlaşılmaktadır.

\section{TEŞEKKÜR}

$\mathrm{Bu}$ çalışma Çukurova Üniversitesi Bilimsel Araştırma Projeleri Birimi tarafından desteklenmiştir (Proje No: FDK-2015-4924).

\section{KAYNAKLAR}

1. ACI Committee, 2015. Guide for the Design and Construction of Structural Concrete Reinforced with Fiber-Reinforced Polymer Bars. ACI440.1R-15, American Concrete Institute, Farmington Hills, MI, 88.

2. Mazaheripour, H., Barros, J.A.O., Soltanzadeh, F., Sena-Cruz, J., 2016. Deflection and Cracking Behavior of SFRSCC Beams Reinforced with Hybrid Prestressed GFRP and Steel Reinforcements, Engineering Structures, 125, 546-565.

3. Refai, A.E., Abed, F., Al-Rahmani, A., 2015. Structural Performance Serviceability of Concrete Beams Reinforced with Hybrid (GFRP and steel) bars, Construction and Building Materials, 96, 518-529.

4. Qin, R., Zhou, A., Lau, D., 2017. Effect of Reinforcement Ratio on the Flexural Performance of Hybrid FRP Reinforced Concrete Beams, Composites Part B, 108, 200-209.

5. Bencardino, F., Condello, A., Ombres, L., 2016. Numerical and Analytical Modelling of Concrete Beams with Steel, FRP and Hybrid FRP-steel Reinforcements, Composite Structures, 140, 53-65.
6. Kara İ. F., Ashour A. F., Koroglu M. A., 2015. Flexural Behavior of Hybrid FRP/Steel Reinforced Concrete Beams. Composite Structures, 129, 111-121.

7. Yinghao, L., Yong, Y., 2013. Arrangement of Hybrid Rebars on Flexural Behavior of HSC Beams. Composites: Part B. 45, 22-31.

8. Unsal, I., Tokgöz, S., Cagatay, I.H., Dundar, C., 2017. A Study on Load-deflection Behavior of Two-span Continuous Concrete Beams Reinforced with GFRP and Steel Bars, Structural Engineering and Mechanics, 63-5, 629-637.

9. Dundar, C., Tanrikulu, A.K., Frosch, R.J., 2015. Prediction of Load-deflection Behavior of Multi-span FRP and Steel Reinforced Concrete Beams, Composite Structures, 132, 680-93.

10. Comité Euro-International Du Béton (CEB), 1990. CEB-FIB Model For Concrete Structures Bulletin, 213/214.

11. Ünsal, İ., Dündar, C., Tanrıkulu, A.K., 2016. Çekme Rijitleşmesinin FRP ve Çelik Donatılı Betonarme Kirişlerin Yük-deplasman Davranışı Üzerindeki Etkisi. Çukurova Üniversitesi Mühendislik Mimarlık Fakültesi Dergisi, 31(1), 429-439. 
